\title{
Assessment of Serum Level of Myostatin in Patients with Androgenetic Alopecia and its Relation to Insulin Resistance
}

\author{
A.A.Ebrahim, A.I.Mustafa, W.A.Abd El-Halim, N.A.El-lithy
}

Dermatology, Venereology and Andrology Dept., Faculty of Medicine, Benha Univ., Benha, Egypt

E-Mail:A.125@gmail.com

\begin{abstract}
Androgenic alopecia influences half of the middle age male occupants, and over $90 \%$ of the mature age men. Myostatin might be adequate to upregulate aggravation in essential human sebocytes. We intended to serum myostatin level in patients with androgenetic alopecia to assess its job in the pathogenesis of the malady and its connection to insulin obstruction. In this work, serum Myostatin levels were evaluated in 30 androgenic alopecia patients. Likewise, relationships of Myostatin with the malady seriousness were researched and 20 evidently sound subjects as controls with mateched age and sex. Serum level of Myostatin and HOMA-IR was estimated in the two gatherings utilizing ELISA. HOMA-IR was altogether higher in AGA when contrasted with control gatherings (mean $=4.7$ versus 2.7; $\mathrm{p}<0.001$ ). No noteworthy distinction was found with respect to FBG and insulin among cases and control gatherings (110.6, versus $82.8, p>0.05 ; 17.3$ versus 13.2; $p>0.05$ ). AGA bunch demonstrated essentially higher Myostatin when contrasted with control gathering (mean=397.5 versus 137.9, $\mathrm{p}<0.001$ ). Myostatin level and HOMA-IR were proposed to be free indicators of AGA helplessness and severity.We prescribed to evaluate the job of Myostatin in pathogenesis of androgenic alopecia.
\end{abstract}

\section{Introduction}

Androgenic alopecia influences half of the middle age male occupants, and over $90 \%$ of the mature age men. It influences almost half of the total populace and about $51 \%$ of the guys matured somewhere in the range of 40 and 75 years [1].

The significant reasons for AGA are DHT and elevated level of testosterone and up somewhat hereditary spread. One thing is imperative to take note of that lone scalp DHT is liable for the hair loss not serum or body tissue-based DHT. In contrast to scalp, DHT created by serum or body tissue may ensure us against going bald and for the most part advance body hair development. High or low degree of testosterone in men doesn't assume job in hair loss. The main thing is the measure of testosterone, which is being changed over to DHT in scalp [1].

Myostatin is related with insulin obstruction. A few exploration bunches have revealed negative relationships between's myostatin levels in skeletal muscle and insulin affectability in human subjects, and myostatin-deficient mice have decreased adiposity and high insulin affectability. This might be brought about by an expanded bulk yet may likewise be because of a more straightforward impact of myostatin on vitality digestion. Infusion of recombinant myostatin in mice for 5 or 7 days caused a decreased insulin affectability [2].

In the course of the most recent couple of years, there has been an expanding enthusiasm for examining the practical jobs of myostatin outside musculoskeletal framework. In such manner, it has been uncovered that myostatin serves significant jobs in the pathogenesis of metabolic issues [3].

The fundamental controllers of the serum levels of myostatin have not yet be to completely distinguished. Stomach corpulence, androgens and skeletal bulk are the significant segments associated with myostatin amalgamation and delivery. In any case, the systems of the relationship between coursing insulin, glucose levels and serum myostatin have stayed to be completely clarified [4].
The point of the current examination is to assess serum myostatin level in patients with androgenetic alopecia to assess its job in the pathogenesis of the illness and its connection to insulin obstruction.

\section{Patient and method}

This examination will incorporate 30 patients experiencing androgenetic alopecia (Group A). Moreover, 20 clearly sound people of coordinated age and sex will be picked as a benchmark (Group B). All patients will be chosen from the outpatient center of Dermatology and Andrology Department of Benha University Hospitals.

\subsection{Ethical considerations}

Composed educated assents will be acquired from all members. The examination will be affirmed by the morals board of trustees on research including human subjects of Benha workforce of Medicine.

\section{Type of the study}

Case-control-study.

\subsection{Inclusion criteria}

Diagnosis of Androgenetic Alopecia will be based on clinical findings, pattern of increased hair thinning on frontal/vertex scalp with greater hair density on occipital scalp zone and will be assessed according to the Hamilton-Norwood classification system for men.

\subsection{Exclusion criteria}

The following patients will be excluded from the study:

- Patients on hormone replacement therapy (e.g. estrogens, progesterone, testosterone, L-thyroxin, or corticoids) during the last 3 months.

- Patients with history of previous diabetes or impaired glucose tolerance.

- Female patients with history of menstrual irregularities. 
- $\quad$ Pregnant and lactating females.

\section{Each patient will be subjected to the following Full history taking}

Including personal, present, past and family history as well as other skin diseases.

\section{Clinical examination}

- Complete general examination including: Body mass index (BMI) and waist circumference.

- Complete cutaneous examination: Clinical assessment of androgenetic alopecia lesions will be done to determine the distribution, grading and the extent of the androgenetic alopecia.

\subsection{Laboratory investigations}

- Estimation of serum fasting glucose level in both androgentic alopecia patients and control group.
- Estimation of serum levels of myostatin and insulin resistance using (ELISA) technique in both androgenetic alopecia patients and control group.

\section{Results}

The AGA group mean age was 31.8 years, they were 12 females $(40 \%)$ and 18 females $(60 \%)$. In addition to 20 healthy control group, their mean age was 27.1 years, they were 7 males (35\%) and 13 females $(65 \%)$. Cases and control groups had matched age and gender ( $p>0.05$ for each).

HOMA-IR was significantly higher in AGA when compared to control groups (mean $=4.7$ versus 2.7; $\mathrm{p}<0.001)$.

No significant difference was found regarding FBG and insulin between cases and control groups (110.6, versus 82.8, $\mathrm{p}>0.05 ; 17.3$ versus $13.2 ; \mathrm{p}>0.05$ ).

AGA group showed significantly higher Myostatin when compared to control group (mean $=397.5$ versus $137.9, \mathrm{p}<0.001)$.

Table (1) Comparison of laboratory data between cases and control groups.

\begin{tabular}{lccccc}
\hline & \multicolumn{2}{c}{ Control N=20 } & \multicolumn{2}{c}{ AGA N=30 } & \multirow{2}{*}{ P } \\
\cline { 2 - 5 } & Mean & SD & mean & SD & \\
\cline { 2 - 5 } Fasting blood glucose $(\mathbf{m g} / \mathbf{d L})$ & 82.8 & 14.9 & 110.6 & 35.9 & 0.175 \\
Fasting insulin (mIU/mL) & 13.2 & 3.6 & 17.3 & 5.5 & 0.197 \\
HOMA-IR & 2.7 & 0.8 & 4.7 & 1.3 & $<0.001$ \\
\hline
\end{tabular}

$\mathrm{SD}$, standard deviation; student $\mathrm{t}$ test was used for numerical parameters.

Table (2) Comparison of Myostatin level between all studied groups.

\begin{tabular}{lccccc}
\hline & \multicolumn{2}{c}{ Control N=20 } & \multicolumn{2}{c}{ AGA N=30 } & P \\
\cline { 2 - 5 } & mean & 土SD & mean & & \\
\cline { 2 - 4 } Myostatin (ng/mL) & 137.9 & 40.1 & 397.5 & & $<0.001$ \\
\hline
\end{tabular}

$\mathrm{SD}$, standard deviation; student $\mathrm{t}$ test was used for numerical parameters.

\section{Discussion}

This is the primary investigation to evaluate level of myostatin according to AGA yet a few past examinations connected between the upregulation of myostatin and a few issues like IR, MS, weight, and type 2 diabetes [5, 6 and 7].

C.Brandt et al., [6], is a case control concentrate on 76 patients with type 2 diabetes and 92 control subjects to survey plasma myostatin and articulation of myostatin in skeletal muscle. Skeletal muscle myostatin mRNA content was 1.4 fold $(\mathrm{P}, 0.05)$ higher in patients with type 2 diabetes when contrasted with the benchmark group. This distinction stayed huge after change for age and sex $(\mathrm{P}, 0.001)$. the investigation uncovered a positive affiliation with respect to muscle myostatin mRNA and the two BMI and insulin obstruction as estimated by HOMA in typical controls subject

Impressive proof has collected that myostatin likewise controls digestion and its restraint can fundamentally constrict the movement of corpulence and diabetes. While at any rate some portion of these consequences for digestion can be inferable from myostatin's impact over skeletal muscle development and subsequently on the all out volume of metabolically dynamic fit weight, there is mounting proof that myostatin influences the development and metabolic condition of different tissues, including the fat and the liver. What's more, ongoing work has investigated the job of myostatin in substrate preparation, take-up as well as use of muscle free of its impacts on body arrangement [5].

Two resulting concentrates by D.S.Hittel and D.S.Hittel et al., [8,9] to exhibit the degrees of myostatin according to corpulence and insulin obstruction. The main investigation included 15 hefty and amazingly corpulent ladies versus 5 lean ladies the outcomes indicated expanded articulation of myostatin protein with outrageous heftiness at the cell, organ, and fundamental level.

The subsequent investigation was done to investigate this relationship in more detail, the creators evaluated myostatin protein in muscle and plasma from 10 insulinsafe, moderately aged $(53.1 \pm 5.5 \mathrm{yr})$ men when a half year of moderate oxygen consuming activity preparing. To build up a reason impact relationship, they additionally infused 
C57/B16 male mice with high physiological degrees of recombinant myostatin protein. The outcomes have demonstrated Myostatin protein levels diminished in muscle $(37 \%, \mathrm{P}=0.042, \mathrm{n}=10)$ and coordinating plasma tests (from $28.7 \mathrm{ng} / \mathrm{mL}$ pretraining to $22.8 \mathrm{ng} / \mathrm{mL}$ posttraining, $\mathrm{P}=0.003, \mathrm{n}=9$ ) with high-impact work out. Moreover, the solid connection between's plasma myostatin levels and insulin affectability $(\mathrm{R} 2=0.82, \mathrm{P} \mathrm{G} \mathrm{0.001,} \mathrm{n}=9$ ) proposed a reason impact relationship that was accordingly affirmed by inciting insulin opposition in myostatin-infused mice. A humble increment (44\%) in plasma myostatin levels was additionally connected with huge decreases in the insulin-invigorated phosphorylation of Akt (Thr308) in both muscle and liver of myostatin-treated creatures [9].

An ongoing report M.Amor et al., [7] intended to research the guideline of myostatin in stoutness and reveal expected relationship between myostatin, metabolic markers and insulin opposition/affectability files. Flowing dynamic myostatin fixation was estimated in the serum of twenty-eight seriously corpulent nondiabetic patients contrasted with a sex and age coordinated lean and overweight benchmark group $(\mathrm{n}=22)$. Insulin opposition/affectability was surveyed in the large gathering. Skeletal muscle and fat tissue examples from the large gathering were gathered during elective bariatric medical procedure. Fat tissue tests from lean and overweight subjects were gathered during elective stomach medical procedure. The outcomes have demonstrated that Myostatin focus was expanded in stout contrasted with lean people, while myostatin fat tissue articulation didn't vary. Muscle myostatin quality articulation was unequivocally connected with articulation of metabolic qualities, for example, IRS1, PGC1 $\alpha$, SREBF1. Besides, flowing myostatin focus connected decidedly with insulin opposition lists and adversely with insulin affectability records .

Myostatin level and HOMA-IR were proposed to be autonomous indicators of AGA vulnerability and severity.We prescribed to survey the job of Myostatin in pathogenesis of androgenic alopecia.

\section{Conclusion}

Myostatin level and HOMA-IR were significantly higher in AGA cases when compared to control group.

Myostatin level and HOMA-IR were significantly correlated with BMI and AGA grades.
Myostatin level and HOMA-IR were suggested to be independent predictors of AGA susceptibility and severity.

\section{References}

[1] D.K.Upadhyay, A.Sharma, G.S.Sarma, Mechanism of Androgenic Alopecia: addressing speculations through empirical evidences. Dermatol Ther, Vol.32(6),PP.52-57,2019.

[2] M.Hjorth, S.Pourteymour, S.W.Görgens , Myostatin in relation to physical activity and dysglycaemia and its effect on energy metabolism in human skeletal muscle cells. Acta Physiologica, Vol.217(1),PP.45-60, 2016.

[3] Zhiqing.Huang, Xiaoling.Chen, Daiwen.Chen,Myostatin: anovel insight into its role in metabolism,signal pathways, and expression regulation.Cellular signaling, Vol.23(9) ,PP.14411446, 2011.

[4] H.Arpaci, Major determinants of circulating myostatin in polycystic ovary syndrome. Experimental and therapeutic medicine, Vol.17(2),PP.1383-1389, 2019.

[5] D.L.Allen, D.S.Hittel and A.C.McPherron , Expression and function of myostatin in obesity, diabetes, and exercise adaptation. Medicine and science in sports and exercise, Vol.43(10),PP. 1828-1832, 2011.

[6] C.Brandt, A.R.Nielsen, C.P.Fischer , Plasma and muscle myostatin in relation to type 2 diabetes. PLoS One;vol 7(5),PP. 371-375, 2012.

[7] M.Amor, B.K.Itariu, M.V.Viedma, Serum myostatin is upregulated in obesity and correlates with insulin resistance in humans. Experimental and Clinical Endocrinology \& Diabetes, Vol.127(08),PP.550-556, 2019.

[8] D.S.Hittel, J.R.Berggren, J.Shearer, Increased secretion and expression of myostatin in skeletal muscle from extremely obese women. Diabetes, Vol.58(1),PP. 30-38, 2009.

[9] D.S.Hittel, M.Axelson, N.Sarna , Myostatin decreases with aerobic exercise and associates with insulin resistance. Medicine and science in sports and exercise, Vol.42(11),PP. 2023, 2010. 